\title{
The effects of acute levodopa withdrawal on motor performance and dopaminergic receptor sensitivity in patients with Parkinson's disease
}

\author{
N Turjanski, W Fernandez, A J Lees
}

\begin{abstract}
The effects of acute levodopa withdrawal were studied in nine patients with levodopa related on-off oscillations. One patient withdrew from the study due to off period confusion and hallucinations. A marked deterioration in motor disability occurred in all patients following overnight withdrawal of levodopa and a further mild delayed deterioration was present over a mean withdrawal period of 44 hours. Patients with more severe disease were able to tolerate levodopa withdrawal for a shorter period of time than those with milder disease severity. The minimum therapeutic dose of subcutaneous apomorphine needed to produce a similar improvement in patients' mobility, before and after several days of drug withdrawal, did not differ, thus providing no clinical evidence for alterations in striatal dopamine receptor sensitivity after acute levodopa withdrawal.
\end{abstract}

$(\mathcal{F}$ Neurol Neurosurg Psychiatry 1993;56:771-775)

Acute levodopa withdrawal for periods of four to ten days has been claimed to temporarily improve drug related motor fluctuations following the reintroduction of levodopa therapy. ${ }^{1-4}$ Proponents of the "drug holiday" have suggested that it reverses the down regulation of striatal dopamine receptor sensitivity believed to occur during dopaminergic longterm treatment. ${ }^{56}$ However, the considerable morbidity seen during the period of levodopa withdrawal, ${ }^{7-9}$ has largely restricted this strategy to patients experiencing drug-induced acute psychotic reactions or toxic confusional states. Despite the considerable literature on acute levodopa withdrawal no pharmacological studies to assess dopaminergic receptor sensitivity before and after drug holidays have been reported.

Delayed deterioration in motor response three to seven days after drug withdrawal is well recognised, and Muenter and Tyce described the existence of a short and a long duration improvement in response to levodopa. The short duration response broadly followed the plasma dopa levels. The long duration response was described when after overnight levodopa withdrawal the motor scores were still above the pre-treatment level, in patients without motor fluctuations or a demonstrable short duration response. ${ }^{10}$

The aim of this study was to evaluate dopaminergic responsiveness and the characteristics of the deterioration that followed levodopa withdrawal, in a group of Parkinson's disease (PD) patients.

\section{Patients and methods}

A) PATIENTS

Nine patients (6 men; 3 women) with Parkinson's disease, after giving informed consent, were admitted to hospital for reassessement of their drug regime and included in a single blind study. All had been followed for several years in the Movement Disorder Clinic of The Middlesex Hospital. Their mean age was 65.5 (54-73) years, mean duration of disease was $14(3-40)$ years and the mean duration of levodopa treatment was 9.6 (1-18) years. All patients had disabling on-off psychomotor fluctuations and six had interdose dyskinesias. At the time of admission the mean Hoehn and Yahr (HY) stage was 3 when on and 3.6 (3-4) when off medication. They received a mean dose of 711 (250-2100) $\mathrm{mg}$ of levodopa a day in combination with a dopa decarboxylase inhibitor. Additionally, five patients were receiving selegiline (mean dose: $10 \mathrm{mg} /$ day) and three benzhexol (mean dose: $5 \cdot 8$ $\mathrm{mg} /$ day).

\section{B) METHODS}

After hospital admission the patient's usual dose of levodopa was given in the form of capsules for three days. During this period, in the off state, patients were challenged with increasing doses of subcutaneous apomorphine, from $1 \mathrm{mg}$ up to the smallest dose capable of producing at least 20 minutes of effective on "mobility". Levodopa therapy was then stopped overnight and the predetermined minimum effective dose of apomorphine administered in the early morning. Following this challenge and unknown to the patient, levodopa was replaced by indistinguishable placebo capsules; other antiParkinsonian drugs were left unchanged. Placebo capsules were continued until each patient developed unacceptable marked deterioration in motor performance, or four days of levodopa withdrawal had ensued. Unacceptable marked deterioration was present when the patient's independence and ability to look after himself were compromised (stage 4 or $5 \mathrm{HY}$ ). Before reintroduction of levodopa, each patient was again challenged with apomorphine to determine the minimum effective "switch on" dose. 
This second challenge started with the same predetermined minimum dose, except in two patients who received $0.5 \mathrm{mg}$ less than on the first injection.

The Modified Webster Scale, timed tapping (unilateral hand tapping over 30 second intervals using two digital counters separated by $20 \mathrm{~cm}$ ) and walking test (the time needed to rise from a chair, walk 6 metres and sit down without help) were assessed every 10 minutes during the apomorphine challenges. The same tests together with the HY score and global clinical evaluation were carried out three times each day (approximately 2 hours after waking, at 9:00 hours, 13:00 hours and 17:00 hours) during the levodopa withdrawal period.

Groups' values were compared using one factor ANOVA-repeated measures, for a $99 \%$ level of confidence and adhoc Scheffe F-test; and Student's paired $t$ statistics.

\section{Results}

\section{EVOLUTION}

One patient withdrew from the study due to severe off period confusion and visual hallucinations occurring after 23 hours of levodopa withdrawal. The average duration of the withdrawal period in the other patients was $44 \cdot 1$ (23-94) hours.

The initial deterioration following an overnight withdrawal of levodopa, after the first apomorphine challenge, was called "first morning off". The final deterioration that occurred at the end of the study, before reintroduction of dopaminergic drugs, was called "last off". The time period between both apomorphine challenges was regarded as the duration of levodopa withdrawal and called long duration deterioration (LDD). The mean group Webster, tapping, HY and timed walking scores at baseline on, first morning off and the last off, at the end of the with-

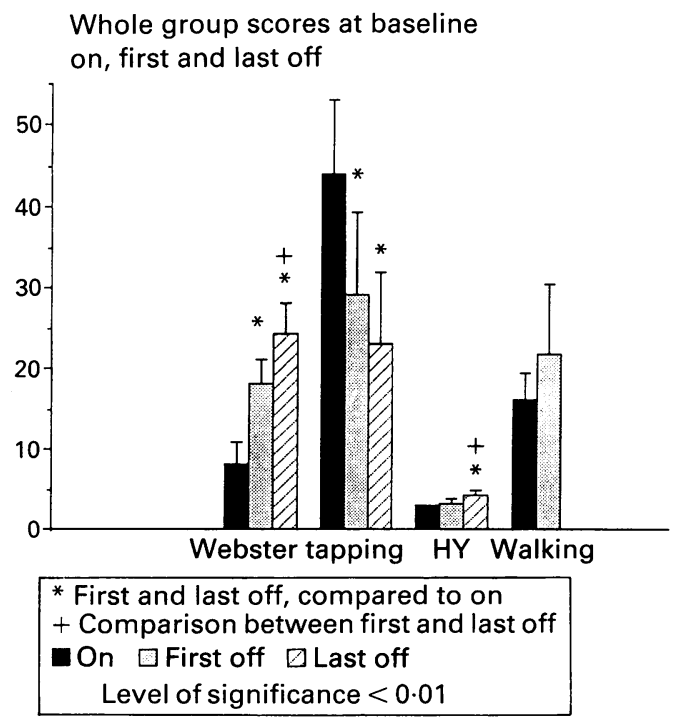

Figure 1 Mean Webster, tapping and HY scores for the eight patients at baseline on, first off after withdrawal and last off, before reintroduction of dopaminergic drugs. By the end of the trial, five patients were unable to walk or arise without help. drawal period are shown in fig 1 . On the first morning off, the Webster and tapping scores showed a significant deterioration, however, the patients mean walking time remained similar [on period: $16 \cdot 2(3 \cdot 2)$ first morning off: $21 \cdot 7(8 \cdot 7)$. By the end of the LDD, there was a significant further increase in the mean Webster [first off: $18 \cdot 2$ (3.0)], last off: $24 \cdot 3$ (3.9)] and the HY scales [First off: $3.3(0.5)$, last off: $4.3(0.7)]$. At the end of the study, five patients were unable to walk or stand up without help. Some sleep benefit occurred each morning, which caused mild fluctuations through the day.

Despite being a small group of patients, two types of LDD were noticed, and the patients were further subdivided depending on the duration of the LDD. Group I included 3 patients, with a mean LDD of 79 (72-94) hours. This group tended to have less deterioration of the motor scores, and a shorter duration of disease (mean 8.6 years) and treatment (mean 5.3 years). One of these patients did not present any significant changes in the scores even after 96 hours without medication, although she did begin to experience increasing pain and discomfort in her legs.
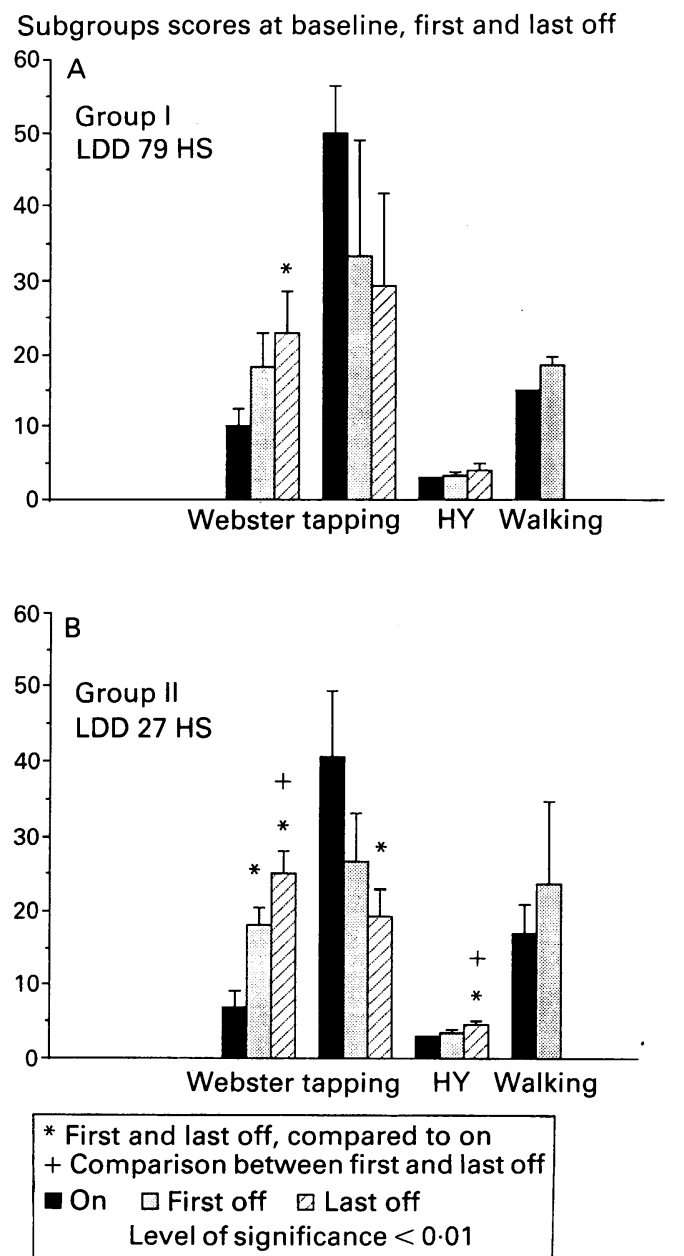

Figure 2 Mean Webster, tapping, HY scores and walking time at baseline on, first off and last off, for groups $I$ (3 patients) and II (5 patients) are represented in $2 a$ and $2 b$, respectively. By the end of the trial, four patients of group I, and one of group II, were unable to walk or arise without help. 
A Evolution of the deterioration
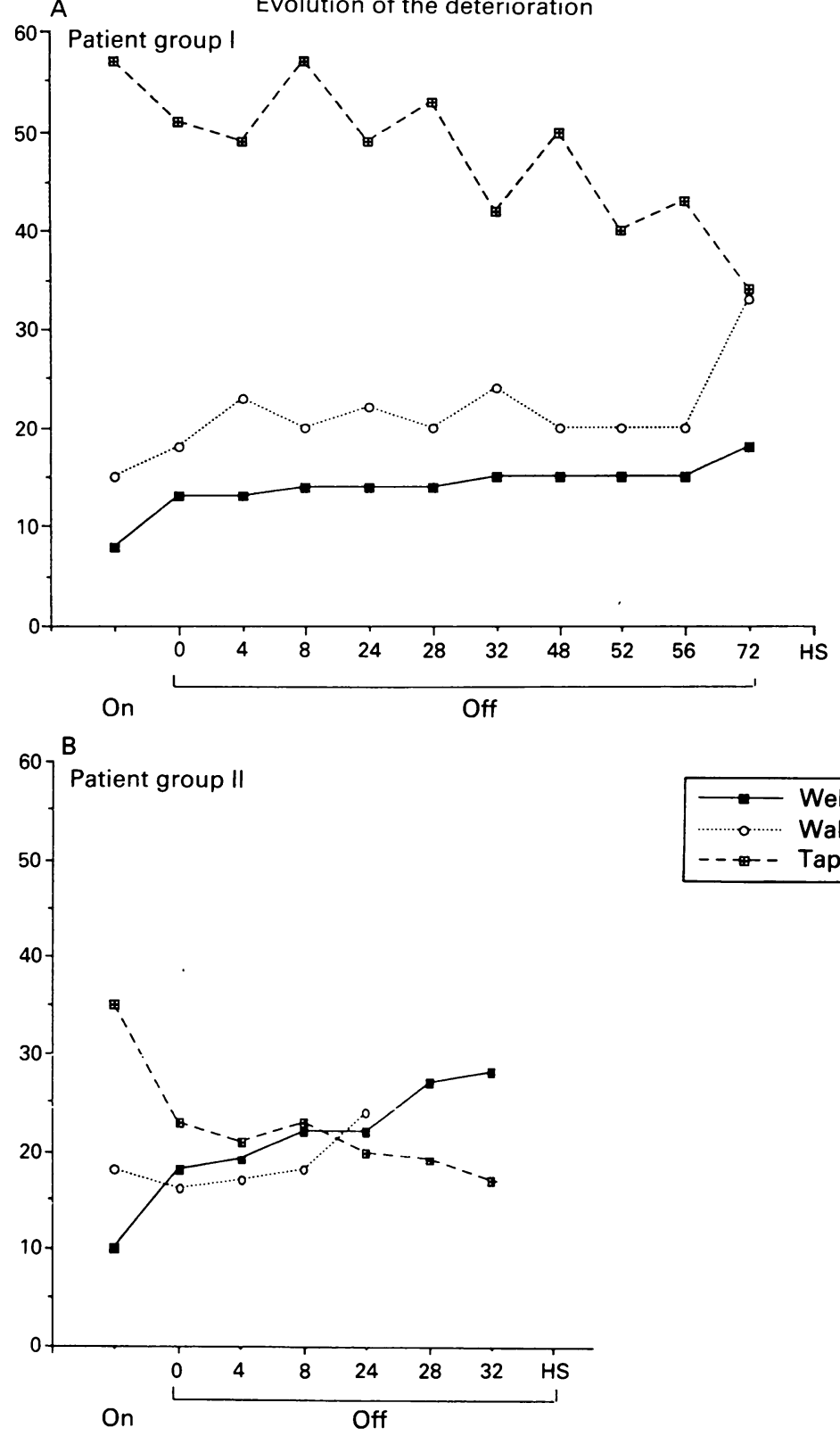

Figure 3 Evolution of the deterioration of the motor scores, for individual patients of group I and II are represented in $3 a$ and $3 b$, respectively.

Group II included 5 patients, with marked worsening of the motor scores after overnight withdrawal and again, at the end of the LDD of a mean $27(25-32)$ hours. This group included patients with a tendency to more severe motor scores, a longer duration of the disease (mean $17 \cdot 2$ years) and longer treatment period (mean 10.6 years). The mean values of both groups are shown in fig 2 , and examples of the evolution of the deterioration in individual patients of each group are displayed in fig 3.

There were no statistical differences in the response to apomorphine, and the duration and severity of the LDD, between patients that continued with and without other antiParkinsonian medication.

APOMORPHINE RESPONSE

Patients were injected with the minimum effective dose of apomorphine, previously found capable of producing at least $20 \mathrm{~min}$ utes of good mobility, before and at the end of the levodopa withdrawal period. The mean therapeutic dose of apomorphine was $4(1 \cdot 5-12) \mathrm{mg}$ at the beginning of the drug holiday and $3 \cdot 8(1-12) \mathrm{mg}$ at the end of the study. Five patients received the same dose of apomorphine before and after the drug holiday, whereas in two patients the dose was reduced by $0.5 \mathrm{mg}$. These two patients did not present any significant differences in latency, duration or quality of response to both apomorphine injections. Five patients increased slightly their latency to switch on during the second challenge: however, the group mean latency remained similar (first challenge: 15 [5-30] minutes, second challenge: 19 [10-30] minutes). Mean duration of apomorphine improvement was 54 (20-77) minutes during the first challenge and 54 (22-90) minutes with the final injection. This duration remained similar for each patient, in three subjects it was between 20 and 40 minutes, and in five between 60 and 90 minutes. No differences occurred between the quality of the on periods and the severity of the dyskinesias during the challenges. Three patients experienced a more severe off stage after apomorphine improvement than at baseline; this was present before and after the levodopa holiday in two subjects.

\section{Discussion}

This study assessed the characteristics of the deterioration induced by levodopa withdrawal in eight PD patients. An enhanced response to the reintroduction of levodopa, after transient drug withdrawal has been claimed by those advocating drug holidays. Sweet et $a l^{1}$ examined the response to $500 \mathrm{mg}$ of levodopa before and after a period of medication withdrawal that varied between 4-11 days. Following the drug holiday they found an increased amplitude of motor response in two of four cases. However, analysis of the data showed that the motor scores after the second levodopa challenge were worse than those found in the baseline state. Klawans et $a l^{2} 6$ assessed a group of patients following levodopa withdrawal (5-7 days) and found that some patients were able to reduce their drug requirements to almost half of the dose. Even on reduced levodopa dose, their motor scores were better nine months later. A group of PD patients after 12 days without levodopa showed a longer duration of the motor response when tested with levodopa and apomorphine, although, the magnitude of the response was smaller. ${ }^{11}$ However Mayeux, ${ }^{12}$ using age and severity of disease matched controls, found no statistical significant improvement six months after a 10 day period, of levodopa withdrawal.

It has been suggested that the clinical improvement observed following drug holidays might be produced by restoring the sensitivity of the dopamine receptors. ${ }^{513}$

Post mortem human studies have shown increased number of putaminal postsynaptic 
dopamine receptors in untreated Parkinsonian brains and reduced numbers in levodopa treated subjects. ${ }^{14-16}$ PET studies in $P D$ patients have shown that the $\mathrm{D}_{2}$ putamen binding potential was normal or increased in untreated patients, and reduced in patients chronically treated. ${ }^{17} 18$ Animal data have shown dopamine receptor upregulation following treatment with reserpine or haloperidol, or after striatal lesions produced with 6-hydroxydopamine. This upregulation was partially or totally reversed after chronic treatment with levodopa or dopamine selective agonists. ${ }^{19-23}$ In rats, $D_{1}$ receptor showed supersensitivity 24 hours after reserpine denervation. ${ }^{24}$ However, Pycock ${ }^{25}$ found that chronic levodopa administration followed by its sudden withdrawal failed to reverse dopamine receptor upregulation in mice previously lesioned with 6-hydroxydopamine.

A test with subcutaneous apomorphine, a dopamine receptor agonist, is currently used in the assessment of dopaminergic responsiveness in Parkinsonian syndromes, it possesses a sensitivity similar to the single levodopa test. ${ }^{26}$ In our study the dose of apomorphine, latency to onset, duration and quality of response did not differ after a period of levodopa withdrawal, providing no clinical evidence for resetting of striatal dopamine receptors. In comparison with some previous clinical studies, the period of levodopa withdrawal in this study, was shorter, with a mean of 44 hours and may have been insufficient to produce receptor changes. However, the time-course of changes in the receptor sensitivity, after levodopa withdrawal, is still uncertain. Improvement in drug related side effects have been reported in Parkinson's disease after levodopa holidays of 2 days every week. ${ }^{28}$ Changes in the sensitivity of the denervated striatum, in animals, were present after a variable length of time, even as early as one day. 162324

Two types of deterioration were observed in our study. The short duration response, may relate to a great extent to the pharmacokinetic properties of levodopa. ${ }^{29}$ On the other hand the delayed deterioration, with a tendency to be more acute in the severely disabled patients, might be attributed to a reduced buffer reserve of dopamine in surviving presynaptic terminals, ${ }^{30}$ or alternatively to mechanisms operating downstream from the postysnaptic striatal receptors.

An interesting observation was the occurrence of transient worsening of disabilities below baseline readings after apomorphine challenges in three patients. This may be explained by an inhibitory effect of threshold doses of dopaminergic drugs. ${ }^{31}$

One patient developed off period confusion and visual hallucinations, a clinical phenomenon which has been previously described. ${ }^{32-35}$ Although temporary levodopa withdrawal may be necessary in most patients with severe toxic confusional states or psychotic reactions occurring during long-term therapy, attempts should be made before drug withdrawal to ascertain whether the confusion is worse when the patient is switched on or in an off period.

In this study there was a deterioration present in all PD patients, after overnight withdrawal of levodopa, but a mild further worsening of the scores occurred with the continuation of the study. Subjects more severely affected had a tendency to faster and more marked deterioration. The acute response to apomorphine before and after the withdrawal was similar.

1 Sweet RD, Lee JE, Spiegel HE, McDowell F. Enhanced response to low doses of levodopa after withdrawal from chronic treatment. Neurology 1972;22:520-5.

2 Koller WC, Weiner WJ, Perlik S, Nausieda PA, Goet CG, Klawans HL. Complications of chronic levodop therapy: Long-term efficacy of drug holiday. Neurology 1981;31:473-6.

3 Friedman JH. Drug holidays in the treatment of Parkinson's disease. A brief review. Arch Intern Med 1985;145:913-5.

4 Klawans HL, Goetz CG, Tanner CM, Nausieda PA Weiner WJ. Levodopa-free periods ("Drug Holidays") in the management of parkinsonism. Adv Neurol in the managem

5 Direnfeld L, Spero L, Marotta J, Seeman P. The L-dopa on-off effect in Parkinson's disease: Treatment by transient drug withdrawal and dopamine recepto resensitization. Ann Neurol 1978;4:573-5.

6 Weiner W, Koller WC, Perlik S, Nausieda PA, Klawan HL. Drug holiday and management of Parkinson disease. Neurology 1980;30:1257-61.

7 Marsden CD, Fahn S. Problems in Parkinson's disease. In: Marsden CD, et al, eds. Movement disorders. Mass:Butterworths Scientific, 1982;1-7.

8 Friedman JH, Feinberg SS, Feldman RG, et al. A neuroleptic malignant-like syndrome due to L-dopa neuroleptic malignant-like syndrome
withdrawal. Ann Neurol 1984;16:126-7.

9 Sechi GP, Tanda F, Mutani R Fatal hyperpyrexia after withdrawal of levodopa. Neurology 1984;34:249-51.

10 Muenter MD, Tyce GM. L-dopa therapy of Parkinson' disease: plasma L-dopa concentration, therapeutic response, and side effects. Mayo Clin Proc 1971;46:231-9.

11 Obeso JA, Lera G, Vaamonde J, et al. Levodopa "drug holidays" improves the "short duration response" in Parkinson's disease. Mov Dis 1992;7(Suppl 1):93.

12 Mayeux R, Stern Y, Mulvey K, Cote L. Reappraisal of temporary levodopa withdrawal ("drug holiday") in Parkinson's disease. N Eng $\mathcal{F}$ Med 1985;313:724-8.

13 Direnfeld LK, Feldman RG, Alexander MP, Kelly-Hayes $M$. Is L-dopa drug holiday useful? Neurology 1980;30:785-8.

14 Lee T, Seeman P, Rajput A, Farley IJ, Hornykiewicz O. Receptor basis for dopaminergic supersensitivity in Parkinson's disease. Nature 1978;273:59-61.

15 Reisine TD, Fields JZ, Yamamura HI. Neurotransmitter receptor alterations in Parkinson's disease. Life Sci 1977;21:335-44

16 Seeman P, Niznik HB. Dopamine receptors and transporters in Parkinson's disease and schizophrenia. FASEB F 1990;21:2737-44

17 Leenders $\mathrm{KL}$, Antonini A. Striatal dopamine $\mathrm{D}_{2}$ receptors in "de novo" parkinsonian patients measured using PET and [11C] raclopride. Neurology 1992;42(Supp 3):295-6

18 Brooks DJ, Ibanez V, Sawle GV, et al. Striatal $\mathrm{D}_{2}$ receptor status in patients with Parkinson's disease, striatonigral degeneration, and progressive supranuclear palsy, measured with "C-raclopride and positron emission tomogsured with "C-raclopride and positron

19 List SJ, Seeman P. Dopamine agonists reverse the ele vated $3 \mathrm{H}$-neuroleptic binding in neuroleptic-pretreated rats. Life Sci $1979 ; 24: 1447-52$.

20 Ezrin-Waters C, Seeman P. L-dopa reversal of hyperdopaminergic behaviour. Life Sci 1991;22:1027-32.

21 Suga $M$. Effect of long-term L-dopa administration on the dopaminergic and cholinergic (muscarinic) receptors of striatum in 6-hydroxydopamine lesioned rats. Life Sci 1980;27:877-82.

22 Reches A, Wagner HR, Jiang D, Jackson V, Fahn S. The effect of chronic L-dopa administration on supersensitive pre- and postsynaptic dopaminergic receptors in rat brain. Life Sci 1982;31:37-44.

23 Britton DR, Kebabian JW, Curzon P. Rapid reversal of denervation supersensitivity of dopamine D1 receptors by L-dopa or a novel dopamine D1 receptor agonist, A68930. European f of Pharmacol 1991;200:89-93.

24 Trugman JM, James CL. Supersensitive metabolic responses to $\mathrm{D}_{1}$ dopamine receptor stimulation occur within 24 hours of dopamine depletion. Neurology 1991;41 (Suppl 1):211. 
25 Pycock CJ, Marsden CD. Central dopaminergic receptor supersensitivity and its relevance to Parkinson's disease. four Neurol Sci 1977;31:113-121.

26 Hughes AJ, Lees AJ, Stern GM. Apomorphine test to predict dopaminergic responsiveness in parkinsonian syndromes. Lancet 1990;336:32-4.

27 Rascol O, Senard JM, Rascol A, Montastruc JL. Apomorphine test in parkinsonian syndromes. Lancet 1990;336:518.

28 Goetz CG, Tanner CM, Nausieda PA. Weekly drug holiday in Parkinson disease. Neurology 1981;31:1460-2.

29 Doller HJ, Connor JD. Changes in neostriatal dopamine concentrations in response

30 Leenders KL, Palmer AJ, Quinn N, Clark JC, Firnau G, Garnett ES. Brain dopamine metabolism in patients Garnett ES. Brain dopamine metabolism in patients
with Parkinson's disease measured with positron emis- sion tomography. 7 Neurol Neurosurg Psychiatry 1986; 49:853-60.

31 Nutt JG, Gancher ST, Woodward WR. Does an inhibitory action of levodopa contribute to motor fluctuations? Neurology 1988;38:1553-7.

32 Steiger MJ, Quinn NP, Toone B, Marsden CD. Offperiod screaming accompanying motor fluctuations in Parkinson's disease. Mov Dis 1991;6:89-90.

33 Sage JI, Duvoisin RC. Sudden onset of confusion with severe exacerbation of Parkinsonism during levodopa therapy. Mov Dis 1986;1:267-70

34 Lang AE. Sudden Confusion with Levodopa withdrawal. Mov Dis 1987;2:223-7.

35 Nissenbaum H, Quinn NP, Brown RG, Toone B Gotham AM, Marsden CD. Mood swings associated with the 'on-off' phenomenon in Parkinson's disease. with the 'on-off' phenomenon
Psychol Med 1987;17:899-904. 